\title{
Analysis of the occurrence and distribution of primary and recurrent basal cell carcinoma of head and neck coupled to the assessment of tumor microenvironment and Sonic hedgehog signaling
}

\author{
Jelena Moisejenko-Golubovica ${ }^{1)}$, Oleg Volkov²), AnNa IVAnOVA ${ }^{3)}$, Valerija Groma ${ }^{4)}$ \\ 1) Department of Doctoral Studies, Riga Stradins University, Riga, Latvia \\ 2) Department of Undergraduate Program, Faculty of Medicine, Riga Stradins University, Riga, Latvia \\ 3) Department of Maxillofacial Surgery, Institute of Stomatology, Riga Stradins University, Riga, Latvia \\ 4) Institute of Anatomy and Anthropology, Riga Stradins University, Riga, Latvia
}

\begin{abstract}
Often, basal cell carcinoma (BCC) displays local aggressiveness, and when developed in the head and neck presents with deep tissue invasion and recurrence. Previous studies have pointed out the necessity of systematic assessment of primary and recurrent BCC based on a better understanding of the biology and function of its microenvironment. Although hedgehog-dependent tumor cells signaling to the underlying stroma, and vice versa, have been demonstrated to be implicated in the pathogenesis of BCC, little is known about peculiarities of the tumor microenvironment and the above-mentioned signaling in the head and neck. The occurrence and distribution of 79 primary and recurrent BCCs developed in the head and neck region were estimated. The data were coupled with the immunohistochemical assessment of type IV collagen, laminin, alpha-smooth muscle actin ( $\alpha$-SMA), and Sonic hedgehog (Shh). The frequency of the mixed BCCs and the predominance of the nose and cheek region affection by primary and recurrent tumors were demonstrated. Furthermore, the increase of peritumoral and entire stromal $\alpha$-SMA immunoreactivity in the mixed recurrent BCC was confirmed using statistics. We found the increase of strong levels of Shh immunoexpression in the aggressive variants of BCC - infiltrative, mixed, and micronodular. Surprisingly, we confirmed the upregulation of Shh paralleled by the downregulation of $\alpha$-SMA immunoexpression in the superficial subtype of the tumor. Our results suggest the necessity of further studies assessing the nature of the tumor along with the peculiarities of signaling in BCCs of head and neck.
\end{abstract}

Keywords: basal cell carcinoma, head and neck, tumor microenvironment, $\alpha$-SMA, Sonic hedgehog.

\section{a Introduction}

Basal cell carcinoma (BCC) is the most common malignant cutaneous neoplasm with an annual incidence increasing worldwide [1]. It develops from cells of the basal epidermal layer and adnexal epithelium $[1,2]$. According to the literature and our observations, the age of patients affected by $\mathrm{BCC}$ has been shifted from 50 to 40 and even 30 years $[1,2]$. The most common histopathological (HP) subtypes of BCC recognized are nodular, mixed, infiltrating, adenoid, micronodular, superficial, and basosquamous with the first two reported to be predominant [3]. Other studies reporting on the incidence of the tumor have demonstrated that the nodular ulcerative subtype represents $40-60 \%$ of BCCs, the superficial type comprises $15-30 \%$ and $1-2 \%$ is the pigmented BCC [4]. Progression of $\mathrm{BCC}$ is slow, and it rarely metastasizes due to its downregulated vascularization $[5,6]$, however, it often appears locally invasive and shows destructive growth [7]. The recurrence rates of $\mathrm{BCC}$ reported by the literature are greatly varying - from $10 \%$ up to $67 \%$ [6, $8,9]$, whereas the distinguished rates of residual tumors vary between $7 \%$ and $45 \%$ [9]. It is worth noting that $\mathrm{BCC}$ has been described not only to spontaneously progress but also regress and disappear $[8,10,11]$, and the potential ability of the residual tumor to regress has been acknowledged previously [8]. It has been pointed out that despite sufficient progress achieved in diagnostics of BCC and progress made in its treatment options, recurrent, aggressive, and metastatic variants of the tumor still pose a significant challenge for the healthcare system [12].

It has been shown that BCC appears intimately connected to its stromal component by use of the basement membrane (BM) molecules, and the interaction between tumor mass and its stroma is essential to the disease pathogenesis. Loss of BM material around individual tumor cell nests occurs with progression from indolentto aggressive-growth BCC [13]. These authors have emphasized that in the superficial and nodular variants of BCC tumor nests are surrounded by a continuous BM comprised of type IV and V collagen admixed with laminin, while infiltrative and morpheaform variants show an absent BM and pronounced stromal desmoplasia. Furthermore, previous studies have demonstrated that the immunoexpression of collagen and laminin, the major molecules of the BM, differs in primary and recurrent BCC [14].

Much success has been achieved in the understanding of the architecture of the tumor microenvironment (TME). A multifaceted structure, which includes: $(i)$ heterogeneous

This is an open-access article distributed under the terms of a Creative Commons Attribution-NonCommercial-ShareAlike 4.0 International Public License, which permits unrestricted use, adaptation, distribution and reproduction in any medium, non-commercially, provided the new creations are licensed under identical terms as the original work and the original work is properly cited. 
cellular constituents both residential, often expressing a fibroblast-like appearance and blood-borne, characterized by phagocytic and immune system cell features; (ii) extracellular matrix molecules and matrix-degrading enzymes, and (iii) sprouting vascular networks have been recognized [15]. Furthermore, recent studies of BCC have demonstrated that the cancer-associated fibroblasts (CAF) expressing different cellular phenotypes appear to be important contributors to the formation of TME [16]. It should be noted that the development of the actin-rich phenotype in stromal cells was demonstrated in aggressive variants of $\mathrm{BCC}$ - micronodular and morpheaform -, when compared to nodular [17]. The results of other studies have suggested an increase of stromal alpha-smooth muscle actin ( $\alpha$-SMA) immunoexpression in aggressive BCCs [5, 18-22]. Various autocrine and paracrine communications between TEM cells and cancer cells are crucial in the initiation and progression of tumors [23]. Other scientists have shown that modern technologies including those assessing the composition of TME might represent novel predictive and prognostic biomarkers in BCC [12].

Sonic hedgehog (Shh) morphogen is an essential regulator of various cellular processes during embryonic and adult life. The mechanism driven by the ligand and leading to tumor development has been extensively explored for more than a decade. Early in the research, the Shh ligand molecule is shown to be implicated as an autocrine signaling factor [24]. Furthermore, induction of the genes regulating epithelial-mesenchymal transition driving tumors to metastasize has been shown when the activation of the hedgehog pathway by the overexpression of zinc finger transcription factors took place $[25,26]$. Previous studies have suggested Shh overexpression leading to pathway activation, tumor proliferation, survival, and/or metastasis [27]. Later, tumor cells were shown to exit a paracrine mechanism secreting Shh and activating the pathway in neighboring stromal cells [28], which were proved to be of myofibroblast lineage. Finally, in inverse paracrine hedgehog activation mode, stromal cells produce the ligand molecules, which bind and activate the signaling pathway in tumor cells [29]. More recent morphological studies have demonstrated the contribution of hedgehog signaling in the pathogenesis of BCC [30]. Since BCC presents with different variants, and tumors developed in the head and neck region often behave more aggressively with deep tissue invasion and recurrence, conduction of studies identifying new prognostic markers of $\mathrm{BCC}$ aggressiveness is very much acknowledged.

\section{Aim}

The purpose of the present study was to analyze the occurrence and distribution of primary and recurrent BCCs of head and neck; to estimate immunohistochemically constituents of the BM - type IV collagen and laminin appearing at the tumoral interface; to assess the biology of cancer cells and TME as a whole by studying $\alpha$-SMA and Shh immunoexpression.

\section{a Patients, Materials and Methods}

Seventy-nine patients presented with BCC of head and neck treated prospectively in Department of Maxillofacial Surgery, Institute of Stomatology, Riga Stradins University, and the Oncology Centre of Latvia from September 1, 2016, to September 1, 2019, were enrolled in this study. In total, 46 female and 33 male patients were enrolled. The age range was $32-95$ years. The clinical data of patients were obtained concerning duration and type of the lesion at the time of presentation, clinical features, anatomic location, and course of the tumor. The skin types were assessed according to the Fitzpatrick Classification Scale [31]. The disease relapse was monitored over a two-year follow-up period. The study was approved by the Ethics Committee of Riga Stradins University, and written informed consent was obtained from all patients. The tumor tissue samples were taken following the tenets of the Declaration of Helsinki.

Dermoscopy was performed before the tumor mass excision. The diagnosis of BCC was confirmed following recommendations of Trigoni et al. (2012) [32], WozniakRito et al. (2018) [33], and Lupu et al. (2019) [34] when fulfilled classical dermoscopy algorithm - lack of pigment network and the presence of at least one of the following criteria: ulceration, maple-leaf like structure, blue-gray globules, blue-ovoid nests, arborizing vessels, and spokewheel structures. Furthermore, we included some additional features recognized as translucency, white areas, and milky pink or red background when diagnosing BCC. Vascular patterns were described as either clustered, diffuse, homogeneous or, sometimes, avascular. Background differences between white-red colors, observed at the lesion sites, are defined as white-red structureless areas as recommended [35].

Only fully excised primary and recurrent BCCs with $10 \mathrm{~mm}$ deep indention into healthy tissue were used in this investigation. Sixty-one of $79(77.2 \%)$ were primary tumors whereas $18(22.8 \%)$ - recurrent BCC. In seven (38.9\%) cases, recurrent BCC developed from the surgically removed primary tumors obtained in a frame of the given study. Patients relapsed in six months up to two years were submitted to re-treatment. Eleven $(61.1 \%)$ patients developed BCC recurrence after the use of less invasive treatment techniques. These less invasive treatment techniques used and recorded were cryotherapy - six cases, $\mathrm{CO}_{2}$ laser treatment - three cases, topical immune response modifier - Imiquimod cream - two cases, respectively. Eight patients presented with the nodulartype BCC, one - with superficial, and two - with basosquamous carcinoma.

Formalin-fixed, paraffin-embedded tumor tissues were processed and sectioned conventionally, and the sections were mounted on HistoBond+ slides (Marienfeld, LaudaKönigshofen, Germany). Consecutive sections were used as negative controls of the immunohistochemical (IHC) reactions, and for Hematoxylin-Eosin (HE) staining to confirm the diagnosis. The histopathology of the tumor was assessed by two independent observers following the World Health Organization (WHO) Classification System for BCC.

IHC reactions were performed using dewaxed and then conventionally treated and processed paraffin sections. Heat-induced antigen retrieval was accomplished with the sections placed in $10 \mathrm{mM}$ citrate buffer for 15 minutes in a vapor lock. Tissue antigens were detected using a panel of primary antibodies: mouse anti-human monoclonal 
$\alpha$-SMA, Abcam, Cambridge, MA, USA, clone 1A4, 1:200), which decorates cells expressing the smooth muscular phenotype [36, 37]; mouse anti-human monoclonal collagen IV (Dako Denmark A/S, Glostrup, Denmark, clone CIV 22, 1:25), which labels the lamina densa of BM [38]; mouse anti-human monoclonal laminin (Dako Denmark A/S, Glostrup, Denmark, clone 4C7, 1:20), which reacts with the laminin family glycoproteins of the epidermal BM [39]; rabbit anti-human monoclonal Shh (Abcam, Cambridge, MA, USA, clone EP1190Y, 1:200), which recognizes full length and c-product subunit of human Shh protein $[40,41]$. The primary antibodies were applied overnight $\left(4^{\circ} \mathrm{C}\right)$ following the manufacturer's recommendations. Amplification of primary antibody and visualization of reaction products was performed applying HiDef Detection Horseradish Peroxidase (HRP) Polymer system (Cell Marque, Rocklin, CA, USA) - after rinsing in phosphate-buffered saline (PBS) solution, sections were incubated with HiDef Detection ${ }^{\mathrm{TM}}$ Amplifier for 10 minutes at room temperature (RT) and HiDef Detection ${ }^{\mathrm{TM}} \mathrm{HRP}$ Polymer Detector for 10 minutes (RT), respectively. Finally, the antigen sites were visualized with 3,3'-Diaminobenzidine (DAB) tetrahydrochloride kit (DAB + Chromogen and $\mathrm{DAB}+$ Substrate buffer, Cell Marque, Rocklin, CA, USA) applied for 5 minutes. Sections were counterstained with Mayer's Hematoxylin, washed, dehydrated, cleared, mounted in Roti ${ }^{\circledR}$ Histokitt (Carl Roth, Karlsruhe, Germany), and coverslipped. Immunolabeling for $\alpha$-SMA was identified by brown stain confined to the cell cytoplasm. Positive immunostaining of Shh was characterized by apparent brown either membranous or membranous/cytoplasmic pattern. The pattern of $\alpha$-SMA and Shh immunoexpression was separately evaluated in the tumor cells and stroma. Immunostaining for type IV collagen and laminin was confined to the BM and displayed a linear (continuous and discontinuous) pattern.

Sections were photographed by a Leica light microscope (Leica DMRB, Leitz Wetzlar, Germany) using a DFC 450C digital camera and scanned by a Glissando Slide Scanner (Objective Imaging Ltd., Cambridge, UK) $0.5 \mu \mathrm{m} /$ pixel resolution with $20 \times$ objective, $0.275 \mu \mathrm{m} /$ pixel resolution with $40 \times$ objective. Therefore, additional reproducible measurements (Aperio ImageScope ver. 12.2.2.5015 software) of tissue immunomarkers along with their spatial distribution were obtained.

The assessment of immunostaining was performed semiquantitatively in 20 randomly selected visual fields of each sample (magnification $400 \times$ ) representing the tumor and stroma of the regions of interest. Overall patterns of collagen IV and laminin immunoexpression were evaluated as showing either absent immunoexpression or extensive discontinuous immunoreactive areas (low levels), discontinuous areas (moderate levels), and continuous immunoexpression (high levels) following recommendations of Agarwal \& Ballabh (2013) [42]. Immunoexpression of these proteins in sebaceous, sweat glands, and blood vessels' walls were not considered in this evaluation. The amount (the percentage of immunopositive cells) for Shh and tumoral $\alpha$-SMA immunostaining was estimated semiquantitatively as (-) negative if no positively stained cells were found; $(+)$ weak if $\leq 10 \% ;(++)$ moderate if $11-50 \%$; $(+++)$ strong if $>51 \%$. Stromal $\alpha$-SMA immunoreactivity was assessed as $(-)$ negative if no staining apart of vascular (for $\alpha$-SMA) was found; (+) weak if only a few myo- fibroblasts showed positivity around the tumor islands; $(++)$ moderate if $<50 \%$ of the islands were surrounded by $\alpha$-SMA-positive cells, and ( +++$)$ strong if $>50 \%$ of the islands were diffusely surrounded by $\alpha$-SMA-positive cells as described previously [18].

Statistical data analysis was performed to assess the immunohistochemistry results and applying Statistical Package for the Social Sciences (SPSS) ver. 24.0 software. To test whether the collected numerical data are normally distributed, a Kolmogorov-Smirnov normality test was applied. The quantitative data were expressed as means \pm standard deviation (SD), whereas categorical parameters were expressed as frequencies and percentages. $P$-values of $<0.05$ were considered significant. The Spearman's rank correlation coefficient was used to estimate the relationships between immunostaining patterns of the antibodies used in this study. The correlation between antigen immunoexpression, pattern of the tumor (primary, recurrent), and HP type of BCC was studied by $\chi^{2}$ (chi-squared) statistics.

\section{ㅁ Results}

Clinically, the skin types were assessed as I-III, according to the Fitzpatrick Classification Scale. No patients with phototype IV-VI were recorded. Out of 79 subjects enrolled in the study, only two $(2.5 \%)$ patients were recognized to have type I, $59(74.7 \%)$ - type II, and $18(22.8 \%)$ - type III. One man and one woman presented with type I. The man has blond hear and blue eyes, the woman - freckles and red hair. Both always burn. Apart from $\mathrm{BCC}$, the man demonstrated multiple actinic keratosis lesions on his face and shoulders. More women -34 out of 59 -, and 25 men presented with type II. Similarly, more women -11 out of 18 -, and seven men presented with type III. Skin easily burned after longer solar exposure when type II was recorded; these patients present with fair skin, light hair, and blue or gray-blue eyes. Patients with phototype III presented with fair to light brown skin color, often dark hair, and varying eye color.

Dermoscopically, primary BCC presented with arborizing vessels, thin and superficial telangiectasias, ulceration with crust formation, shiny white and milky-pink regions, and sometimes - blue-gray ovoid nests (Figure 1). Shiny whiteand-red structureless areas suspected as more fibrotic were further correlated with the HP findings. Short white streaks were common in mixed and recurrent BCC (Figure 2).

Among 79 patients, 15 (19\%) presented with the nodular HP subtype of the tumor, $18(23 \%)$ - superficial, 10 (12\%) - infiltrative, seven (9\%) - micronodular subtype, and 29 $(37 \%)$ - mixed subtype. The most frequent combinations of the mixed BCCs included nodular-infiltrative, superficialnodular, and nodular-micronodular subtype. No statistical differences in gender distribution were found among histological subtypes $(p=0.102)$. The distribution of BCC by anatomical location and histological subtype is presented in Table 1. Analysis of the anatomical location of the lesion confirmed that the nose and cheek were predominant regions affected by both primary and recurrent tumors constituting $36.7 \%$ and $29.1 \%$, respectively. Furthermore, according to our study, the nose area was very susceptible to tumor recurrence - nine of $18(50 \%)$ cases. The second half of recurrent tumors presented with five BCCs on the cheek, three on the eyelid, and one - on the ear. In our study, the third most often lesioned region was the eyelid (10.1\%). 


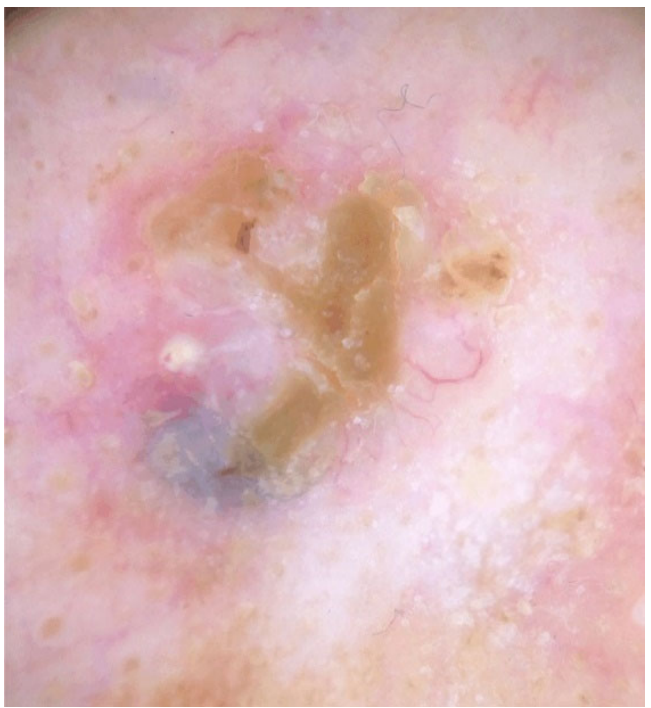

Figure 1 - A well-defined, pearl, translucent nodule with a homogeneous milky-pink background and arborized blood vessels; tumor surface with crust over a wound, milia-like cyst, and blue-gray ovoid nest demonstrated dermoscopically in the case of primary nodular basal cell carcinoma.

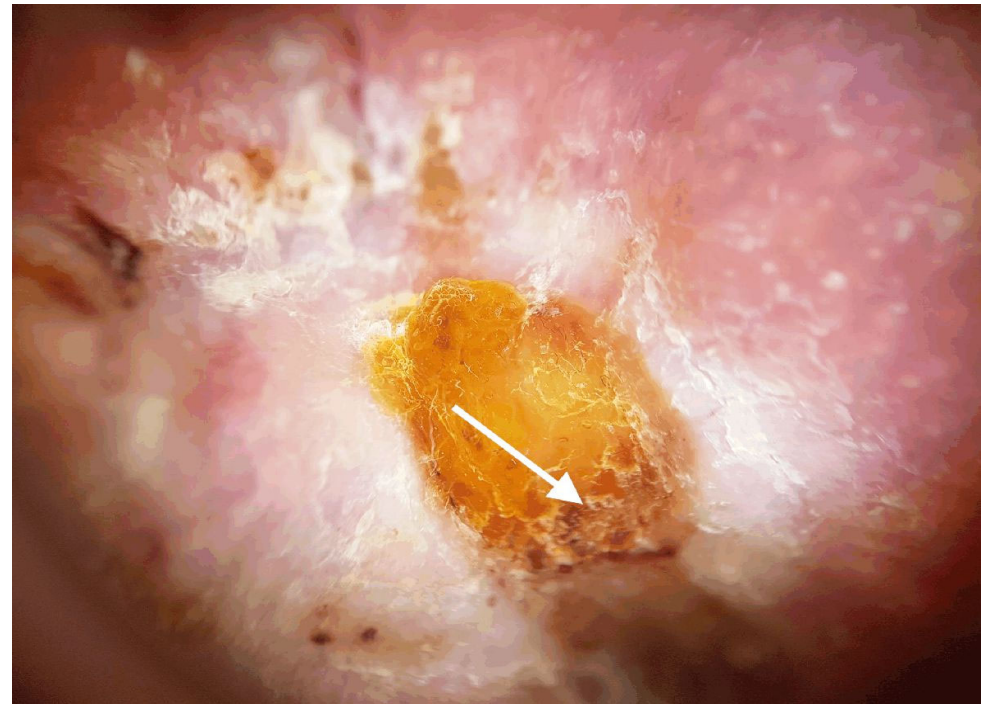

Figure 2 - A homogeneous white-to-pink coloration of the area of interest and ulceration (white arrow) demonstrated dermoscopically in the case of recurrent basal cell carcinoma.

Table 1 - Distribution of primary and recurrent BCCs by histological subtype and anatomical location

\begin{tabular}{|c|c|c|c|c|c|c|c|c|c|c|c|c|}
\hline \multirow{2}{*}{\multicolumn{3}{|c|}{$\begin{array}{c}\text { Description of } \\
\text { sample/diagnosis }\end{array}$}} & \multicolumn{9}{|c|}{ Anatomical location } & \multirow{2}{*}{ Total } \\
\hline & & & Nose & Temple & Cheek & Eyelid & Scalp & Lip & Ear & Neck & Forehead & \\
\hline \multirow{6}{*}{ Primary } & \multirow{6}{*}{ Type } & $\mathrm{N}$ & 6 & 1 & 2 & 1 & 2 & 0 & 1 & 1 & 0 & 14 \\
\hline & & $\mathrm{MN}$ & 2 & 0 & 2 & 1 & 0 & 0 & 1 & 0 & 1 & 7 \\
\hline & & 1 & 2 & 2 & 3 & 0 & 0 & 0 & 1 & 0 & 0 & 8 \\
\hline & & $S$ & 4 & 0 & 7 & 1 & 1 & 0 & 0 & 0 & 0 & 13 \\
\hline & & $\mathrm{MIX}$ & 6 & 1 & 4 & 2 & 0 & 2 & 1 & 1 & 2 & 19 \\
\hline & & & 20 & 4 & 18 & 5 & 3 & 2 & 4 & 2 & 3 & 61 \\
\hline \multirow{5}{*}{ Recurrent } & \multirow{4}{*}{ Type } & $\mathrm{N}$ & 0 & & 1 & 0 & & & 0 & & & 1 \\
\hline & & $\mathrm{I}$ & 2 & & 0 & 0 & & & 0 & & & 2 \\
\hline & & $S$ & 0 & & 2 & 2 & & & 1 & & & 5 \\
\hline & & $\mathrm{MIX}$ & 7 & & 2 & 1 & & & 0 & & & 10 \\
\hline & To & & 9 & & 5 & 3 & & & 1 & & & 18 \\
\hline \multirow{6}{*}{ Total } & \multirow{6}{*}{ Type } & $\mathrm{N}$ & 6 & 1 & 3 & 1 & 2 & 0 & 1 & 1 & 0 & 15 \\
\hline & & MN & 2 & 0 & 2 & 1 & 0 & 0 & 1 & 0 & 1 & 7 \\
\hline & & 1 & 4 & 2 & 3 & 0 & 0 & 0 & 1 & 0 & 0 & 10 \\
\hline & & $S$ & 4 & 0 & 9 & 3 & 1 & 0 & 1 & 0 & 0 & 18 \\
\hline & & MIX & 13 & 1 & 6 & 3 & 0 & 2 & 1 & 1 & 2 & 29 \\
\hline & & & 29 & 4 & 23 & 8 & 3 & 2 & 5 & 2 & 3 & 79 \\
\hline
\end{tabular}

I: Infiltrative subtype; MIX: Mixed subtype; MN: Micronodular subtype; N: Nodular subtype; S: Superficial subtype.

Nodular (in primary tumors) and mixed BCCs (in primary and recurrent tumors) were prevalently located in the nose than other head and neck regions constituting $42.9 \%, 31.6 \%$, and $70 \%$, respectively. Furthermore, the prevalence of the mixed subtype in nasal recurrent $\mathrm{BCC}$ was very high - seven of $10(70 \%)$ cases. In micronodular subtype, the anatomical location was: nose, two $(29 \%)$; cheek, two (29\%); eyelid, one (14\%); ear, one (14\%), and forehead, one (14\%), whereas the specific site of superficial BCC was: cheek, nine (50\%); nose, four (22\%); eyelid, three $(17 \%)$; scalp, one $(5.5 \%)$; and ear, one $(5.5 \%)$. Infiltrative recurrent BCCs presented exclusively with the nasal location, while primary tumors were distributed as follows - cheek, three (38\%); nose, two (25\%); temple, two $(25 \%)$, and ear, one (12\%).
Histopathologically, nodular BCC presented as large islands with peripheral palisading of cells, clefting between the collagenous stroma, tumor necrosis, and focal cystic changes. Microscopic presentation of micronodular subtype revealed small tumor nests with less obvious palisading and connection to the epidermis, whereas superficial showed irregular proliferation of the basal cells budding from the epidermis, but infiltrative - cord-like, elongated strands of tumor cells infiltrating between collagen bundles.

Initially, analysis of the IHC results was consistent with the detection of immunoexpression levels of major molecules of the BM - type IV collagen and laminin establishing a barrier restricting the dissemination of tumor cells. Contours of tumor masses labeled by the anti-laminin (Figure 3) and anti-collagen IV (Figure 4) antibodies for 
the presence of these molecules displayed a linear but greatly varying immunostaining pattern - both continuous and discontinuous. A discontinuous or absent immunostaining pattern was often revealed in the infiltrative BCCs. Levels of type IV collagen and laminin immunoexpression were similarly distributed varying from low to moderate and high $-60.3 \%, 35.6 \%, 4.1 \%$, and $71.1 \%, 25.2 \%, 3.6 \%$ for collagen IV and laminin, respectively.

The results of the IHC expression of $\alpha$-SMA and Shh estimated for tumoral and stromal compartments of primary and recurrent tumors are summarized in Table 2, whereas - in different HP subtypes of BCCs studied - in Table 3.

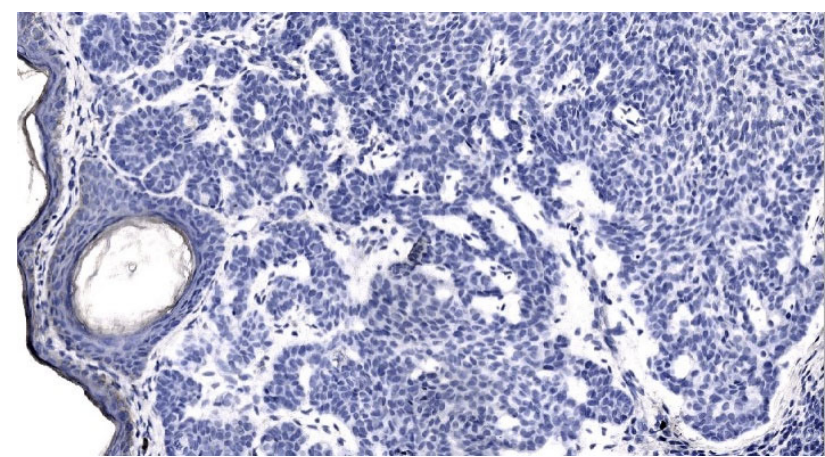

Figure 3 - Weak continuous laminin immunoexpression appearing along the basal aspect of the surface and follicular epithelium, the immunoexpression within the basement membrane delineating differently sized and shaped nodules and micronodules of the mixed recurrent tumor is almost nil. Laminin immunohistochemistry, $\times 200$.
Levels of the tumoral $\alpha$-SMA immunoexpression were distributed varying from weak to moderate and strong. Simultaneously, we confirmed a decrease in weak stromal $\alpha$-SMA immunoexpression levels in recurrent BCC when compared to primary BCC, followed by two times higher strong stromal $\alpha$-SMA immunoexpression levels demonstrated in recurrent BCC (Table 2). Comparing the levels of $\alpha$-SMA immunoexpression in primary and recurrent BCCs studied, we found statistically significant differences for both tumoral and stromal compartments $\left(\chi^{2}=16.191\right.$; $\mathrm{df}=2 ; \quad p<0.0001 ; \quad$ and $\left.\chi^{2}=26.510 ; \quad \mathrm{df}=2 ; \quad p<0.0001\right)$, respectively.

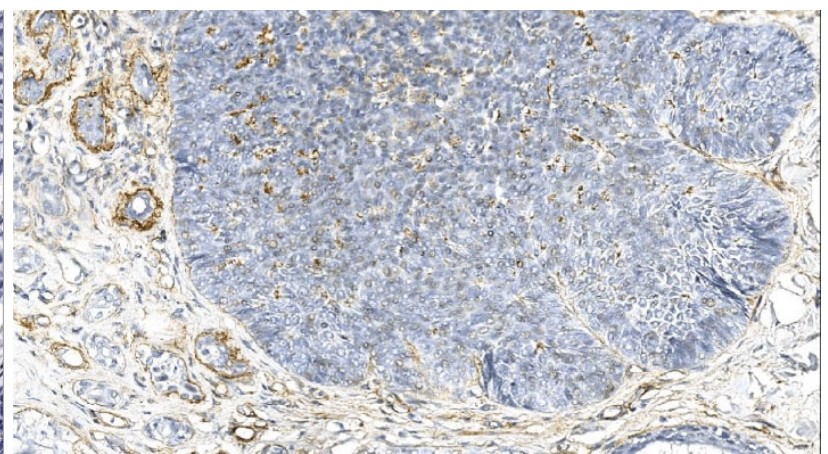

Figure 4 - The linear and both continuous and discontinuous immunostaining decorating the base of the tumor nests and vascular beds of the mixed recurrent tumor. Type IV collagen immunohistochemistry, $\times 250$.

Table 2 - Distribution of $\alpha-S M A$ and Shh immunoexpression levels in primary and recurrent BCCs

\begin{tabular}{|c|c|c|c|c|c|c|c|}
\hline \multirow{3}{*}{$\begin{array}{l}\text { Description of } \\
\text { sample/diagnosis }\end{array}$} & \multicolumn{7}{|c|}{ Antigens } \\
\hline & \multirow{2}{*}{ Location } & \multicolumn{3}{|c|}{$\alpha-S M A$} & \multicolumn{3}{|c|}{ Shh } \\
\hline & & Weak & Moderate & Strong & Weak & Moderate & Strong \\
\hline Primary BCC & \multirow{2}{*}{ Tumor } & $627(58.0 \%)$ & $274(25.3 \%)$ & $181(16.7 \%)$ & $347(33.2 \%)$ & $344(32.9 \%)$ & $355(33.9 \%)$ \\
\hline Recurrent BCC & & $195(60.2 \%)$ & $52(16.0 \%)$ & $77(23.8 \%)$ & $96(30.8 \%)$ & $101(32.5 \%)$ & $114(36.7 \%)$ \\
\hline Primary BCC & \multirow{2}{*}{ Stroma } & $914(75.2 \%)$ & $216(17.8 \%)$ & $85(7.0 \%)$ & $929(76.1 \%)$ & $223(18.3 \%)$ & $68(5.6 \%)$ \\
\hline Recurrent BCC & & $243(67.5 \%)$ & $60(16.7 \%)$ & $57(15.8 \%)$ & $259(72.0 \%)$ & $67(18.6 \%)$ & $34(9.4 \%)$ \\
\hline
\end{tabular}

$\alpha$-SMA: Alpha-smooth muscle actin; BCC: Basal cell carcinoma; Shh: Sonic hedgehog. *The shown numerical data represent the number of visual fields estimated and demonstrated either weak or moderate and strong expression of antigen.

When compared to $\alpha$-SMA, levels of the tumoral Shh immunoexpression were almost equally distributed and varied from weak to moderate and strong for primary and recurrent BCC (Table 2). Similarly to $\alpha$-SMA assessment, we found an increase in strong stromal Shh immunoexpression levels in recurrent BCC. Comparing the levels of Shh immunoexpression in primary and recurrent BCCs studied, we found statistically significant differences for stromal but not tumoral compartment $\left(\chi^{2}=7.121 ; \mathrm{df}=2\right.$; $p=0.028$; and $\chi^{2}=0.915 ; \mathrm{df}=2 ; p=0.633$ ), respectively.

We found that one-fourth of neoplastic cells within the samples demonstrating infiltrative BCC subtype revealed a strong level of $\alpha$-SMA immunoexpression followed by one-fifth in the nodular, and the mixed subtype (Table 3). Simultaneously, almost one-fifth of the stroma of infiltrative subtype revealed a strong of $\alpha$-SMA immunoexpression followed by one-tenth in the mixed, and around one-tenth in micronodular subtype. Tumor masses and stroma of the superficial subtype revealed a negligible amount of neoplastic epithelial and stromal cells displaying a strong level of $\alpha$-SMA immunoexpression. Furthermore, when assessing the $\alpha$-SMA immunoexpression displayed in different HP subtypes of BCCs, we found that nodular BCC demonstrated a weak to moderate and rarely a strong level of $\alpha$-SMA immunopositivity within tumor nests and cords (Figure 5) paralleled by very weak or almost nil stromal reactivity (Figure 6). By contrast, micronodular, mixed and infiltrative subtype of BCC often demonstrated a marked, strong stromal $\alpha$-SMA immunoexpression presented either as a diffuse or a peritumoral (Figure 7), heavily decorating the base of tumor nests (Figure 8). In the case of diffuse immunoexpression, some mixed tumors presented with actin-rich stroma enveloping $\alpha$-SMA negative tumors nests and strands (Figure 9).

The superficial subtype presented with a weak $\alpha$-SMA immunoexpression, both tumoral and stromal, furthermore, the last one often diminished in areas with inflammatory infiltration (Figure 10). Comparing $\alpha$-SMA immunoexpression in subtypes of BCC, we found that tumoral immunoexpression revealed in the superficial subtype significantly differed when compared to all other subtypes - nodular $(p<0.0001)$, micronodular $(p=0.003)$, infiltrative 
$(p<0.0001)$, and mixed $(p<0.0001)$. Similarly, stromal immunoexpression revealed in the infiltrative subtype significantly differed when compared to all other subtypes nodular $(p<0.0001)$, micronodular $(p=0.036)$, superficial $(p<0.0001)$, and mixed $(p<0.001)$.

Similarly to $\alpha$-SMA immunoexpression, nodular tumoral masses demonstrated mostly weak Shh immunopositivity accompanied by extremely weak stromal immunoreactivity
(Figure 11). Of note, that almost one half of infiltrative BBCs, followed by more than one-third of superficial and mixed tumors, and about one-third of micronodular displayed a strong Shh immunoexpression within neoplastic buds and strands (Figure 12), whereas the others - moderate to strong Shh immunoexpression (Figure 13). The highest stromal immunoexpression of Shh was found in the superficial subtype of BCC (Figure 14).

Table 3 - Distribution of a-SMA and Shh immunoexpression levels in different histopathological subtypes of BCCs

\begin{tabular}{cccccccc}
\hline \multirow{2}{*}{$\begin{array}{c}\text { Histopathological } \\
\text { subtype of BCC }\end{array}$} & Location & \multicolumn{5}{c}{ Antigens } \\
\cline { 2 - 7 } & & Weak & Moderate & Strong & Weak & Moderate & Strong \\
\cline { 2 - 7 } & Tumor & $132(51.2 \%)$ & $69(26.7 \%)$ & $57(22.1 \%)$ & $127(47.2 \%)$ & $86(32.0 \%)$ & $56(20.8 \%)$ \\
\cline { 2 - 7 } Nodular & Stroma & $221(75.0 \%)$ & $55(18.6 \%)$ & $19(6.4 \%)$ & $262(87.3 \%)$ & $36(12.0 \%)$ & $2(0.7 \%)$ \\
\hline \multirow{2}{*}{ Micronodular } & Tumor & $75(59.5 \%)$ & $33(26.2 \%)$ & $18(14.3 \%)$ & $53(41.4 \%)$ & $37(28.9 \%)$ & $38(29.7 \%)$ \\
\cline { 2 - 7 } & Stroma & $100(71.4 \%)$ & $28(20.0 \%)$ & $12(8.6 \%)$ & $103(73.6 \%)$ & $28(20.0 \%)$ & $9(6.4 \%)$ \\
\hline \multirow{2}{*}{ Infiltrative } & Tumor & $92(49.5 \%)$ & $48(25.8 \%)$ & $46(24.7 \%)$ & $39(22.5 \%)$ & $56(32.4 \%)$ & $78(45.1 \%)$ \\
\cline { 2 - 7 } & Stroma & $120(60.0 \%)$ & $45(22.5 \%)$ & $35(17.5 \%)$ & $135(67.5 \%)$ & $53(26.5 \%)$ & $12(6.0 \%)$ \\
\hline \multirow{2}{*}{ Superficial } & Tumor & $210(79.5 \%)$ & $43(16.3 \%)$ & $11(4.2 \%)$ & $52(23.8 \%)$ & $83(38.1 \%)$ & $83(38.1 \%)$ \\
\cline { 2 - 7 } & Stroma & $289(80.3 \%)$ & $55(15.3 \%)$ & $16(4.4 \%)$ & $265(73.6 \%)$ & $61(16.9 \%)$ & $34(9.4 \%)$ \\
\hline \multirow{2}{*}{ Mixed } & Tumor & $313(54.7 \%)$ & $133(23.3 \%)$ & $126(22.0 \%)$ & $172(30.2 \%)$ & $183(32.2 \%)$ & $214(37.6 \%)$ \\
\cline { 2 - 7 } & Stroma & $427(73.6 \%)$ & $93(16.0 \%)$ & $60(10.4 \%)$ & $423(72.9 \%)$ & $112(19.3 \%)$ & $45(7.8 \%)$ \\
\hline
\end{tabular}

a-SMA: Alpha-smooth muscle actin; BCC: Basal cell carcinoma; Shh: Sonic hedgehog. *The shown numerical data represent the number of visual fields estimated and demonstrated either weak or moderate and strong expression of antigen.

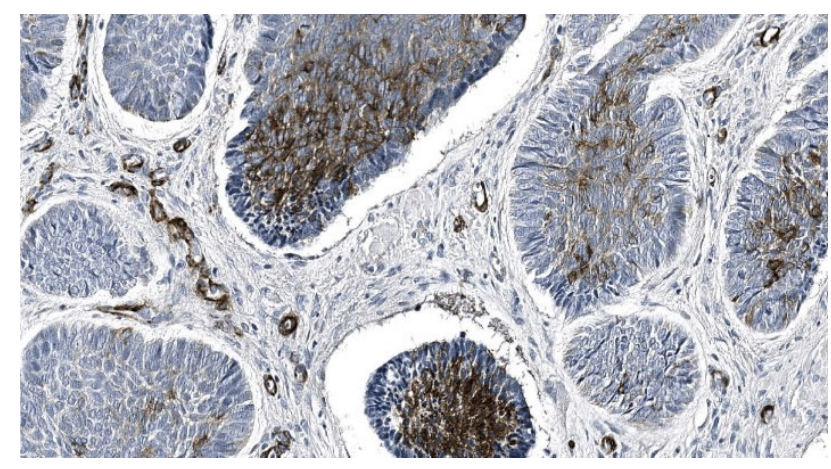

Figure 5 - Solid nodules of primary BCC demonstrate rather diffuse, weak to moderate a-SMA immunopositivity, whereas the lower one - more strong and compact immunopositivity appearing locally. Vascular a-SMA immunopositivity appears in myxoid stroma interspersing the nodules. $\alpha-S M A$ immunohistochemistry, $\times 250 . \alpha-S M A$ : Alpha-smooth muscle actin; BCC: Basal cell carcinoma.

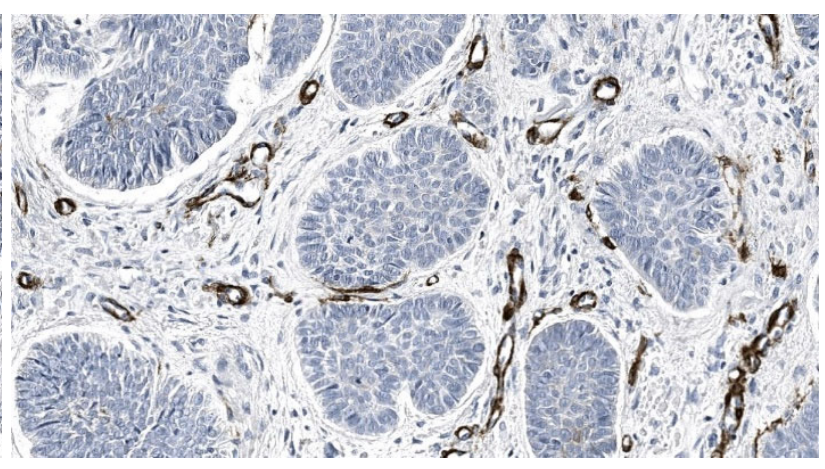

Figure 6 - Immunoexpression of a-SMA, both tumoral and stromal, is almost nil; $\alpha-S M A$ immunopositivity is restricted to vascular appearing in myxoid stroma interspersing the nodules of this primary BCC. $\alpha-S M A$ immunohistochemistry, $\times 250 . \alpha-S M A:$ Alpha-smooth muscle actin; BCC: Basal cell carcinoma.

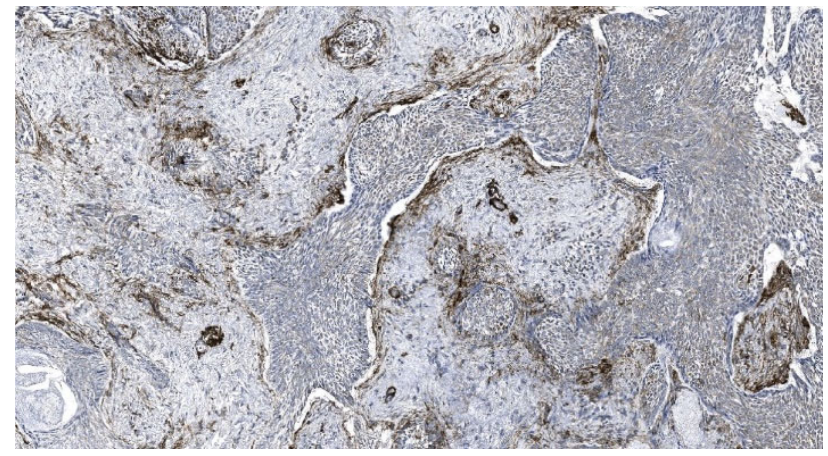

Figure 7 - Low power view of mixed recurrent BCC demonstrating stromal peritumoral and vascular $\alpha-S M A$ immunoexpression appearing in the myxoid stroma. $\alpha-S M A$ immunohistochemistry, $\times 100 . \alpha-S M A:$ Alphasmooth muscle actin; BCC: Basal cell carcinoma.

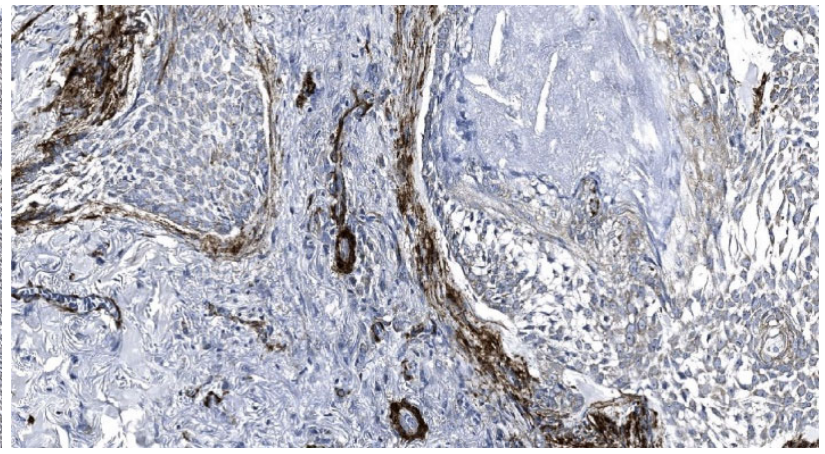

Figure 8-Strong stromal peritumoral immunoexpression of $\alpha-S M A$ displayed as a heavy decoration at the base of tumor nests and cords observed in mixed recurrent $B C C$; $\alpha-S M A$ immunopositivity within vascular channels. $\alpha-S M A$ immunohistochemistry, $\times 200 . \alpha-S M A$ : Alphasmooth muscle actin; BCC: Basal cell carcinoma. 


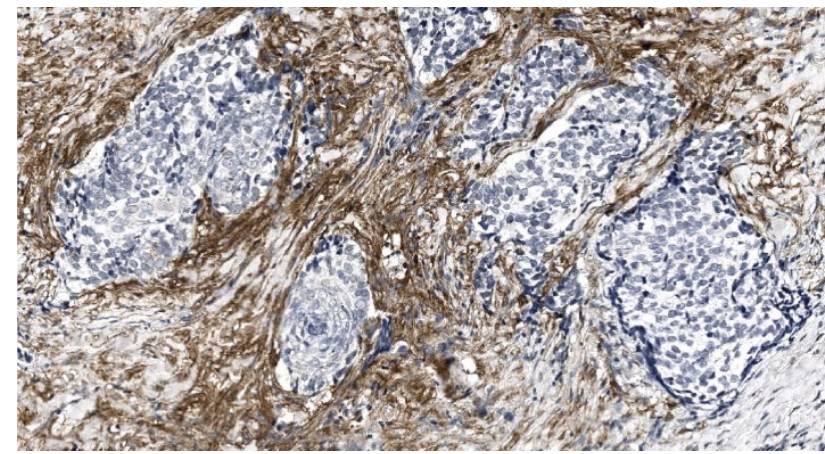

Figure $9-\alpha-S M A$ immunonegative tumor nests and strands of mixed recurrent $B C C$ are surrounded by actinrich stroma. $\alpha-S M A$ immunohistochemistry, $\times 200 . \alpha-S M A$ : Alpha-smooth muscle actin; BCC: Basal cell carcinoma.

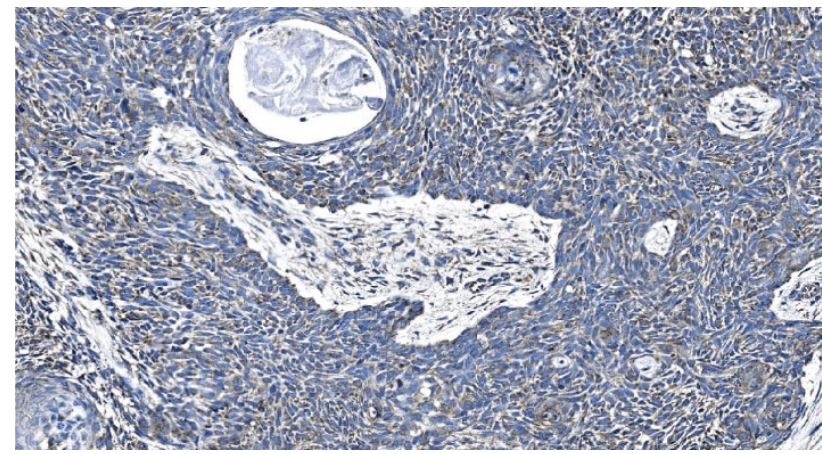

Figure 11 - Nodular BCC masses displaying a weak immunoexpression of Shh; stromal immunoexpression is almost nil. Shh immunohistochemistry, $\times 250$. BCC: Basal cell carcinoma; Shh: Sonic hedgehog.

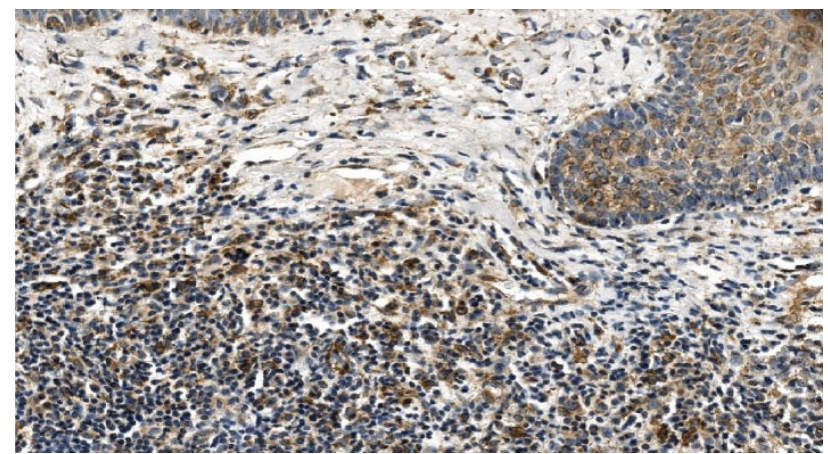

Figure 13 - Moderate to a strong tumoral immunoexpression of Shh accompanied by weak to moderate stromal immunoexpression observed in primary superficial BCC; marked stromal infiltration. Shh immunohistochemistry, $\times 250$. BCC: Basal cell carcinoma; Shh: Sonic hedgehog.

The levels of Shh assessed for both BCC compartments differed when compared to $\alpha$-SMA levels. Moderate and strong levels of the tumoral Shh immunoexpression characterized infiltrative, superficial, mixed, and micronodular subtypes (Table 3 ). Simultaneously, stromal Shh levels were three times lower but two times higher for infiltrative and superficial subtype, respectively, when compared to $\alpha$-SMA levels. Comparing Shh immunoexpression in subtypes of BCC studied, we found that

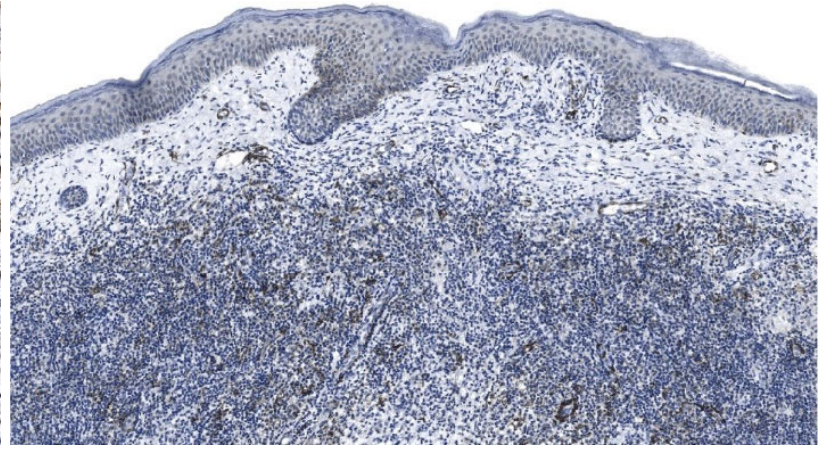

Figure 10 - Weak tumoral immunoexpression of $\alpha-S M A$ observed in primary superficial BCC; stroma is heavily infiltrated with inflammatory cells, and $\alpha-S M A$ immunopositivity is restricted to vascular beds. $\alpha-S M A$ immunohistochemistry, $\times 100 . \alpha-S M A$ : Alpha-smooth muscle actin; BCC: Basal cell carcinoma.

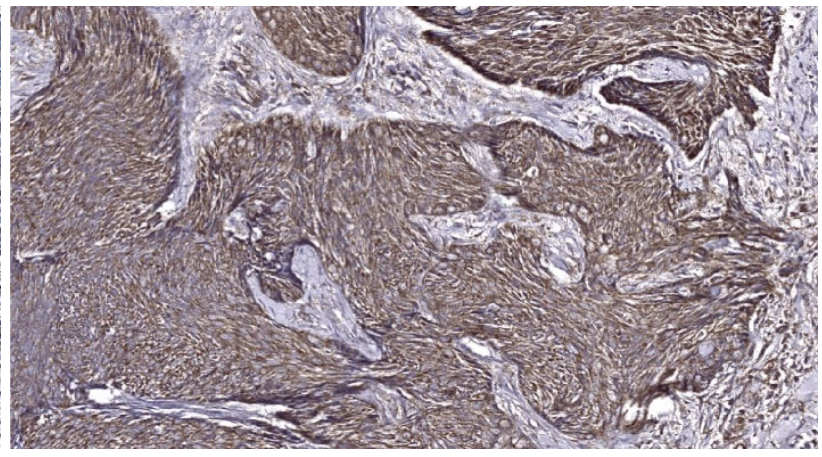

Figure 12 - Mixed primary BCC demonstrates tumor strands revealing partial stromal invasion and heavily decorated with the anti-Shh antibody; stromal component exhibits Shh immunopositivity as well. Shh immunohistochemistry, $\times 200$. BCC: Basal cell carcinoma; Shh: Sonic hedgehog.

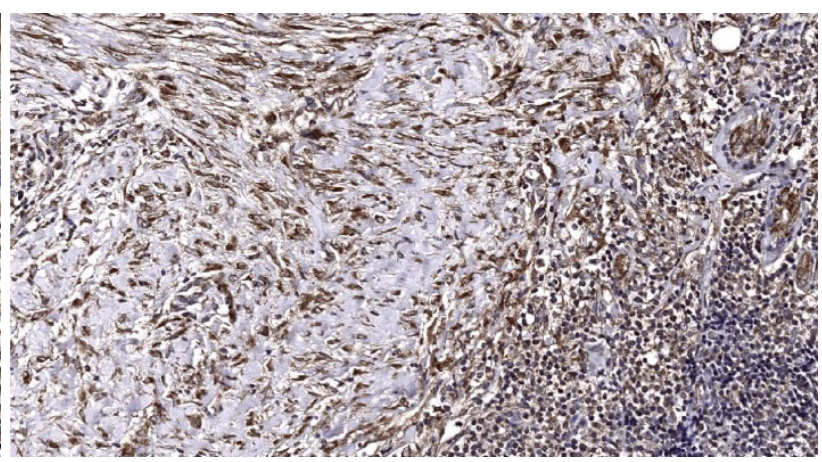

Figure 14-Diffuse, rather regular moderate stromal Shh immunoexpression demonstrated in primary superficial BCC. Shh immunohistochemistry, $\times 200$. BCC: Basal cell carcinoma; Shh: Sonic hedgehog.

tumoral immunoexpression revealed in the nodular subtype significantly differed when compared to all other subtypes except micronodular - infiltrative $(p<0.0001)$, superficial $(p<0.0001)$, and the mixed $(p<0.0001)$. Stromal immunoexpression revealed in the nodular subtype significantly differed when compared to all other subtypes - infiltrative $(p<0.0001)$, micronodular $(p=0.009)$, superficial $(p<0.0001)$, and mixed $(p<0.0001)$. 


\section{ㅁ Discussions}

In the present study, we have ( $i$ ) assessed the occurrence and distribution of 79 primary and recurrent BCCs developed in the head and neck region; (ii) performed IHC analysis of major constituents of the BM - type IV collagen and laminin - enveloping the tumoral compartment, and (iii) analyzed the immunoexpression of $\alpha$-SMA and Shh found in the bulk of the tumor and surrounding stroma in different subtypes of BCC, reflecting the complexity of the biology and signaling in this neoplasm.

A high frequency of BCC constituting approximately $80 \%$ of all nonmelanoma skin cancers, and commonly appearing on the head and neck - body areas exposed to the sun has been demonstrated previously $[1,2,6]$. Simultaneously, the absolute incidence of BCC has not been determined, since non-melanoma skin cancer is usually excluded from cancer-registry statistics [1]. Furthermore, HP characteristics of BCC of the head and neck have changed over time, and new studies deepening our knowledge about the biology of BCC, in general, and behavioral peculiarities of TME, in particular, have been encouraged.

In many studies reviewed, men were affected more often than women, whereas the reported age was over 60 years at the first presentation $[1,43,44]$. We found the gender distribution similar to that reported by Mawardi et al. [45] and demonstrating female predominance, whereas the age at the time of diagnosis was similar comparing this study to former ones.

Assessing skin phototype in patients enrolled in the given study, we found type II to be most common. It is characteristic of the inhabitants living in the Baltic region. Simultaneously, subjects with I-III skin phototype are recognized as having a higher risk to develop skin cancer [46].

In the present study, we have demonstrated that $\mathrm{BCC}$ might cause severe damage due to its local recurrence, and the mid-face is more susceptible. The nose, the cheek, and the eyelid areas chronically exposed to sunlight were more often affected by both primary and recurrent tumors than BCCs on the other predilection sites. These results are in accordance with those demonstrated by Mawardi et al. [45] when local, but not distant recurrence and aggressiveness of BCC were studied. In this context, the need for a comprehensive follow-up along with the correctness of complete tumor excision and application of Mohs micrographic surgery at the first surgical appointment are pivotal issues in reducing the likelihood of recurrence $[47,48]$.

Heterogeneity of the histopathology of BCC has been evidenced by other authors and us [49]. Furthermore, a high proportion of mixed $\mathrm{BCC}$ exhibiting an aggressive growth pattern and requiring surgical excision with margin control was demonstrated by the previous and current study [50]. Histomorphologically, infiltrative, morpheaform, micronodular, and superficial BCC, as surprisingly appeared in the given study, share some common features of aggressiveness - increased cell necrosis, mitotic rate, and stromal cell proliferation, lesser stromal retraction, deeper invasion, and less circumscription of the tumor [51].

Our evidence regarding the entire structure of the $\mathrm{BM}$, as exemplified by collagen IV and laminin immuno- expression, appears to be similar to that published in the available literature $[52,53]$. Similarly to the previous studies, we found that levels of type IV collagen and laminin immunoexpression were varying from low to moderate and high, with about two-thirds presented by low levels. The immunoexpression of the BM molecules studied was discontinuous or absent in $\mathrm{BCC}$ areas showing an aggressive pattern of growth.

Previous studies have pointed out the necessity of tumor assessment based on an understanding of the biology and function of TME [54]. Furthermore, the usefulness of estimation of the cellular constituents of TME using the IHC assessment has been demonstrated very recently in studies of local aggressiveness in BCC [55]. The development of the actin-rich phenotype in $\mathrm{CAF}$ colonizing stromal compartment in aggressive variants of $\mathrm{BCC}-$ micronodular and morpheaform - was demonstrated previously $[5,20]$, and our IHC findings appear to support this evidence. Furthermore, recent results obtained by Romanian researchers in the case of the upper lip BCC suggest the usefulness of $\alpha$-SMA immunoreactivity assessment on the invasion front [22]. This is consistent with the results of the present study confirming the increase of peritumoral and entire stromal $\alpha$-SMA immunoreactivity in mixed recurrent BCC. Unfortunately, very few studies have reported on $\alpha$-SMA assessments coupled to statistical evaluation of the immunomarker expression demonstrated either in tumoral and stromal compartments found in various subtypes of BCC or the primary and recurrent tumors [18]. Our study based on careful statistical assessments of the immunomarkers studied provided the meaningful evidence - the appearance of strong stromal $\alpha$-SMA immunoexpression levels demonstrated in the recurrent BCC should be interpreted with caution considering the relapsing nature of the tumor.

Activation of Shh signaling in the TME and its association with tumor growth and metastatic activity has been shown in studies examining the morphogen expression in neoplasms [56, 57]. Previous studies have suggested enhancement of resting fibroblasts stimulation and conversion into myofibroblasts by Shh, leading to the accumulation of collagen and dermal thickening in mice [58]. Furthermore, the frequency of hedgehog-related genetic alterations in $\mathrm{BCC}$ has been demonstrated recently, proving the presence of paracrine signaling in the TME harboring CAF [29, 59].

As described above, very limited data about the Shh signaling in primary and recurrent $\mathrm{BCC}$, when the various subtypes of the tumor are compared statistically, have been reported. In this study, we have assessed the levels of Shh in primary and recurrent, and in five different subtypes of BCC by use of immunohistochemistry and statistics. We proved the increase of strong levels of Shh immunoexpression in both - tumoral and stromal compartments. Furthermore, when specifying the subtypes of BCC analyzed, we found the increase of strong levels of Shh immunoexpression in aggressive variants infiltrative, mixed, and micronodular. These results agree with the data demonstrated by Casas et al. [60]. By contrast, among the other subtypes of BCC, previously considered as aggressive variants, we found upregulation of Shh paralleled by downregulation of $\alpha$-SMA immunoexpression 
in the superficial subtype of the tumor assumed to be nonaggressive. This leads us to propose that Shh participates in normal and affected epidermal homeostasis, but the molecular pathway of the signaling is not completely understood. Finally, we may suggest that the assessment of morphological and IHC characteristics of primary and recurring forms of skin cancer and possible changes in the properties of a tumor is important for determining prognostic factors and choosing an adequate method for treating a disease. Shh binds to the patched receptor, which, in turn, functions in association with smoothened, to activate the transcription of target genes. Therefore, target therapy of hedgehog-related cancers, including $\mathrm{BCC}$, is on its way to a much broader clinical application [59, 61-63]. Continued investigation of these processes will likely reveal new mechanisms of $\mathrm{BCC}$ and TME regulation with implications well beyond the control of Shh signaling.

\section{Conclusions}

The given study deepens our knowledge regarding clinical, dermoscopical, and morphological assessment of primary and recurrent BCCs of head and neck, and explores the peculiarities of TME and Shh signaling in these tumors. Two-thirds of the patients enrolled in the study presented with skin phototype II. The nose and cheek are predominant regions affected by both primary and recurrent tumors. The proportion of patients with BCC developed in the nose area and relapsed after two years is high; it points out the necessity of precise surgical excision and HP assessment, especially when mixed tumors are considered. BCCs defined as infiltrative, micronodular, and superficial, as surprisingly appeared in the given study, are more aggressive. These often present with discontinuous BM and stromal CAF bearing actin-rich phenotype. The increase of peritumoral and entire stromal $\alpha$-SMA immunoreactivity in BCC should be interpreted with special caution. Activation of Shh signaling in aggressive variants of $\mathrm{BCC}$ contributes, at least partly, to the changes of nature and interactions of the TME constituents.

\section{Conflict of interests}

The authors declare no conflict of interests.

\section{Acknowledgments}

Riga Stradins University Department of Doctoral studies and Roche Latvia are acknowledged for reagents and publishing support.

\section{Authors' contribution}

Conceptualization, Jelena Moisejenko-Golubovica (J.M.-G.); formal analysis, J.M.-G.; Oleg Volkov (O.V.); data curation, J.M.-G.; O.V.; Valerija Groma (V.G.); writing - original draft preparation, J.M.-G.; Anna Ivanova (A.I.); writing - review and editing, J.M.-G.; V.G.; immunohistochemistry, O.V., V.G.; patients' recruitment and surgery, J.M.-G.; A.I.; dermoscopy, J.M.-G.

\section{References}

[1] Rubin Al, Chen EH, Ratner D. Basal-cell carcinoma. N Engl J Med, 2005, 353(21):2262-2269. https://doi.org/10.1056/NEJM ra044151 PMID: 16306523
[2] Carucci JA, Leffell DJ. Basal cell carcinoma. In: Wolff $K$, Goldsmith LA, Katz SI, Gilchrest BA, Paller AS, Leffell DJ (eds). Fitzpatrick's dermatology in general medicine. $7^{\text {th }}$ edition, McGraw-Hill Medical Publisher, New York, 2008, 1036-1042.

[3] Koyuncuer A. Histopathological evaluation of non-melanoma skin cancer. World J Surg Oncol, 2014, 12:159. https://doi. org/10.1186/1477-7819-12-159 PMID: 24886534 PMCID: PMC4046093

[4] Daya-Grosjean L, Couvé-Privat S. Sonic hedgehog signaling in basal cell carcinomas. Cancer Lett, 2005, 225(2):181-192. https://doi.org/10.1016/j.canlet.2004.10.003 PMID: 15978322

[5] Mercuţ R, Ciurea ME, Mărgăritescu C, Popescu SM, Crăiţoiu MM, Cotoi OS, Voinescu DC. Expression of p53, D2-40 and $\alpha$-smooth muscle actin in different histological subtypes of facial basal cell carcinoma. Rom J Morphol Embryol, 2014, 55(2):263-272. PMID: 24969973

[6] Lara F, Santamaría JR, Garbers LE. Recurrence rate of basal cell carcinoma with positive histopathological margins and related risk factors. An Bras Dermatol, 2017, 92(1):58-62. https:// doi.org/10.1590/abd1806-4841.20174867 PMID: 28225958 PMCID: PMC5312180

[7] Omland SH, Nielsen PS, Gjerdrum LMR, Gniadecki R. Immunosuppressive environment in basal cell carcinoma: the role of regulatory T cells. Acta Derm Venereol, 2016, 96(7):917-921. https://doi.org/10.2340/00015555-2440 PMID: 27117439

[8] Griffiths RW, Suvarna SK, Stone J. Do basal cell carcinomas recur after complete conventional surgical excision? Br J Plast Surg, 2005, 58(6):795-805. https://doi.org/10.1016/j.bjps.2005. 02.010 PMID: 16086990

[9] Ríos-Buceta L. [Management of basal cell carcinomas with positive margins]. Actas Dermosifiliogr, 2007, 98(10):679687. https://doi.org/10.1016/S1578-2190(07)70540-1 PMID: 18035025

[10] Franchimont C, Pierard GE, Van Cauwenberge D, Damseaux M, Lapiere $\mathrm{CH}$. Episodic progression and regression of basal cell carcinomas. Br J Dermatol, 1982, 106(3):305-310. https:// doi.org/10.1111/j.1365-2133.1982.tb01728.x PMID: 7066190

[11] Swetter SM, Boldrick JC, Pierre P, Wong P, Egbert BM. Effects of biopsy-induced wound healing on residual basal cell and squamous cell carcinomas: rate of tumor regression in excisional specimens. J Cutan Pathol, 2003, 30(2):139-146. https://doi.org/10.1034/j.1600-0560.2003.000002.x PMID: 12641794

[12] Lupu M, Caruntu C, Ghita MA, Voiculescu V, Voiculescu S, Rosca AE, Caruntu A, Moraru L, Popa IM, Calenic B, Greabu M, Costea DE. Gene expression and proteome analysis as sources of biomarkers in basal cell carcinoma. Dis Markers, 2016, 2016:9831237. https://doi.org/10.1155/2016/9831237 PMID: 27578920 PMCID: PMC4992754

[13] Garcia C, Poletti E, Crowson AN. Basosquamous carcinoma. J Am Acad Dermatol, 2009, 60(1):137-143. https://doi.org/ 10.1016/j.jaad.2008.09.036 PMID: 19103364

[14] Marasà L, Marasà S, Sciancalepore G. Collagen IV, laminin, fibronectin, vitronectin. Comparative study in basal cell carcinoma. Correlation between basement membrane molecules expression and invasive potential. G Ital Dermatol Venereol, 2008, 143(3):169-173. PMID: 18833058

[15] Peltanova B, Raudenska M, Masarik M. Effect of tumor microenvironment on pathogenesis of the head and neck squamous cell carcinoma: a systematic review. Mol Cancer, 2019, 18(1):63. https://doi.org/10.1186/s12943-019-0983-5 PMID: 30927923 PMCID: PMC6441173

[16] Sasaki K, Sugai T, Ishida K, Amano H, Kimura H, Sakuraba M, Kashiwa K, Kobayashi S. Analysis of cancer-associated fibroblasts and the epithelial-mesenchymal transition in cutaneous basal cell carcinoma, squamous cell carcinoma, and malignant melanoma. Hum Pathol, 2018, 79:1-8. https:// doi.org/10.1016/j.humpath.2018.03.006 PMID: 29555579

[17] Christian MM, Moy RL, Wagner RF, Yen-Moore A. A correlation of alpha-smooth muscle actin an invasion in micronodular basal cell carcinoma. Dermatol Surg, 2001, 27(5):441-445. https:// doi.org/10.1046/j.1524-4725.2001.00200.x PMID: 11359490

[18] Bozdogan O, Erkek E, Atasoy P, Koçak M, Birol A, Caydere M. $\mathrm{Bcl}$-2-related proteins, alpha-smooth muscle actin and amyloid deposits in aggressive and non-aggressive basal cell carcinomas. Acta Derm Venereol, 2002, 82(6):423-427. https:// doi.org/10.1080/000155502762064548 PMID: 12575847 
[19] Pilloni L, Bianco P, Manieli C, Senes G, Coni P, Atzori L, Aste N Faa G. Immunoreactivity for alpha-smooth muscle actin characterizes a potentially aggressive subgroup of little basa cell carcinomas. Eur J Histochem, 2009, 53(2):e14. https:// doi.org/10.4081/ejh.2009.e14 PMID: 30256877 PMCID: PMC3167285

[20] Adegboyega PA, Rodriguez S, McLarty J. Stromal expression of actin is a marker of aggressiveness in basal cell carcinoma. Hum Pathol, 2010, 41(8):1128-1137. https://doi.org/10.1016/ j.humpath.2009.12.014 PMID: 20381122

[21] Lau J, Guminski A, Gill A, Veivers D. Metastatic basal cell carcinoma: a review of six cases. Aust J Otolaryngol, 2018, 1:20. https://doi.org/10.21037/ajo.2018.09.05

[22] Sălan Al, Mărăşescu PC, Camen A, Ciucă EM, Matei M, Florescu $A M$, Pădureanu $V$, Mărgăritescu $C$. The prognostic value of CXCR4, $\alpha$-SMA and WASL in upper lip basal cell carcinomas. Rom J Morphol Embryol, 2018, 59(3):839-849. PMID: 30534824

[23] Roma-Rodrigues C, Mendez R, Baptista PV, Fernandes AR. Targeting tumor microenvironment for cancer therapy. Int $\mathrm{J}$ Mol Sci, 2019, 20(4):840. https://doi.org/10.3390/ijms20040 840 PMID: 30781344 PMCID: PMC6413095

[24] Evangelista M, Tian H, de Sauvage FJ. The hedgehog signaling pathway in cancer. Clin Cancer Res, 2006, $12(20 \mathrm{Pt}$ 1):59245928. https://doi.org/10.1158/1078-0432.CCR-06-1736 PMID: 17062662

[25] Beachy PA, Karhadkar SS, Berman DM. Tissue repair and stem cell renewal in carcinogenesis. Nature, 2004, 432(7015): 324-331. https://doi.org/10.1038/nature03100 PMID: 15549094

[26] Sanchez P, Hernández AM, Stecca B, Kahler AJ, DeGueme AM, Barrett A, Beyna M, Datta MW, Datta S, Ruiz i Altaba A. Inhibition of prostate cancer proliferation by interference with Sonic Hedgehog-Gli 1 signaling. Proc Natl Acad Sci U S A, 2004, 101(34):12561-12566. https://doi.org/10.1073/pnas.04 04956101 PMID: 15314219 PMCID: PMC514658

[27] Berman DM, Karhadkar SS, Maitra A, Montes De Oca R, Gerstenblith MR, Briggs K, Parker AR, Shimada Y, Eshleman JR, Watkins DN, Beachy PA. Widespread requirement for Hedgehog ligand stimulation in growth of digestive tract tumours. Nature, 2003, 425(6960):846-851. https://doi.org/10.1038/nature01 972 PMID: 14520411

[28] Caro I, Low JA. The role of the hedgehog signaling pathway in the development of basal cell carcinoma and opportunities for treatment. Clin Cancer Res, 2010, 16(13):3335-3339. https:// doi.org/10.1158/1078-0432.CCR-09-2570 PMID: 20439455

[29] Hanna A, Shevde LA. Hedgehog signaling: modulation of cancer properties and tumor mircroenvironment. Mol Cancer, 2016 15:24. https://doi.org/10.1186/s12943-016-0509-3 PMID: 26988232 PMCID: PMC4797362

[30] Celebi ARC, Kiratli H, Soylemeoglu F. Evaluation of the 'Hedgehog' signaling pathways in squamous and basal cell carcinomas of the eyelids and conjunctiva. Oncol Lett, 2016, 12(1):467-472. https://doi.org/10.3892/ol.2016.4625 PMID: 27347166 PMCID: PMC4907170

[31] Fitzpatrick TB. The validity and practicality of sun-reactive skin types I through VI. Arch Dermatol, 1988, 124(6):869-871. https:// doi.org/10.1001/archderm.124.6.869 PMID: 3377516

[32] Trigoni A, Lazaridou E, Apalla Z, Vakirlis E, Chrysomallis F, Varytimiadis $D$, loannides $D$. Dermoscopic features in the diagnosis of different types of basal cell carcinoma: a prospective analysis. Hippokratia, 2012, 16(1):29-34. PMID: 23930054 PMCID: PMC3738389

[33] Wozniak-Rito A, Zalaudek I, Rudnicka L. Dermoscopy of basal cell carcinoma. Clin Exp Dermatol, 2018, 43(3):241-247. https:// doi.org/10.1111/ced.13387 PMID: 29341291

[34] Lupu M, Caruntu C, Popa MI, Voiculescu VM, Zurac S, Boda D. Vascular patterns in basal cell carcinoma: dermoscopic, confocal and histopathological perspectives. Oncol Lett, 2019 17(5):4112-4125. https://doi.org/10.3892/ol.2019.10070 PMID: 30944604 PMCID: PMC6444327

[35] Enache AO, Pătraşcu V, Simionescu CE, Ciurea RN, Văduva A Stoica LE. Dermoscopy patterns and histopathological findings in nodular basal cell carcinoma - study on 68 cases. Curr Health Sci J, 2019, 45(1):116-122. https://doi.org/10.12865/ CHSJ.45.01.16 PMID: 31297272 PMCID: PMC6592668

[36] Skalli O, Ropraz P, Trzeciak A, Benzonana G, Gillessen D, Gabbiani G. A monoclonal antibody against alpha-smooth muscle actin: a new probe for smooth muscle differentiation.
J Cell Biol, 1986, 103(6 Pt 2):2787-2796. https://doi.org/10. 1083/jcb.103.6.2787 PMID: 3539945 PMCID: PMC2114627

[37] Wu J, Hong Y, Wu T, Wang J, Chen X, Wang Z, Cheng B, Xi J. Stromal epithelial lactate shuttle induced by tumor-derived interleukin- $1 \beta$ promotes cell proliferation in oral squamous cell carcinoma. Int J Mol Med, 2018, 41(2):687-696. https://doi. org/10.3892/ijmm.2017.3267 PMID: 29207019 PMCID: PMC 5752169

[38] Lammers G, Verhaegen PDHM, Ulrich MMW, Schalkwijk J, Middelkoop E, Weiland D, Nillesen STM, Van Kuppevelt TH, Daamen WF. An overview of methods for the in vivo evaluation of tissue-engineered skin constructs. Tissue Eng Part B Rev, 2011, 17(1):33-55. https://doi.org/10.1089/ten.TEB.2010.0473 PMID: 21050145

[39] Wondimu Z, Omrani S, Ishikawa T, Javed F, Oikawa Y, Virtanen I, Juronen E, Ingerpuu S, Patarroyo M. A novel monoclonal antibody to human laminin $a 5$ chain strongly inhibits integrin-mediated cell adhesion and migration on laminins 511 and 521. PLoS One, 2013, 8(1):e53648. https://doi.org/10. 1371/journal.pone.0053648 PMID: 23308268 PMCID: PMC 3538678

[40] McCann CK, Growdon WB, Kulkarni-Datar K, Curley MD, Friel AM, Proctor JL, Sheikh H, Deyneko I, Ferguson JA, Vathipadiekal V, Birrer MJ, Borger DR, Mohapatra G, Zukerberg LR, Foster R, Macdougall JR, Rueda BR. Inhibition of Hedgehog signaling antagonizes serous ovarian cancer growth in a primary xenograft model. PLoS One, 2011, 6(11): e28077. https://doi.org/10.1371/journal.pone.0028077 PMID: 22140510 PMCID: PMC3226669

[41] Kaminagakura E, Almeida JD, Carvalho YR, Franco RC, Soares FA, Rocha RM, Kowalski LP. Keratocyst of the buccal mucosa: case report and immunohistochemical comparative study with sporadic intraosseous keratocystic odontogenic tumor. Oral Surg Oral Med Oral Pathol Oral Radiol, 2013 , 116(5):e387-e392. https://doi.org/10.1016/j.000o.2013.02.005 PMID: 23669203

[42] Agarwal P, Ballabh R. Expression of type IV collagen in different histological grades of oral squamous cell carcinoma: an immunohistochemical study. J Cancer Res Ther, 2013, 9(2):272-275. https://doi.org/10.4103/0973-1482.113382 PMID: 23771372

[43] Holtmann H, Fuhrmann V, Sander K, Sproll C, Kübler NR, Singh DD, Lommen J. Histopathological and patient-related characteristics of basal cell carcinomas of the head and neck influencing therapeutic management. Dermatol Reports, 2018, 10(2):7674. https://doi.org/10.4081/dr.2018.7674 PMID: 30603060 PMCID: PMC6291759

[44] Vaca-Aguilera MR, Guevara-Gutiérrez E, Barrientos-García JG, Tlacuilo-Parra A. Giant basal cell carcinoma: clinical-histological characteristics of 115 cases. Int J Dermatol, 2019, 58(12): 1430-1434. https://doi.org/10.1111/ijd.14455 PMID: 30972736

[45] Mawardi P, Kalim H, Kalim KH, Fitri LE, Mintaroem K, Mudigdo A, Oyong, Wasita B. Mid-face location of primary basal cell carcinoma related to cancer aggressivity. Asian Pac J Trop Dis, 2016, 6(8):650-653. https://doi.org/10.1016/S22 22-1808(16)61103-9

[46] Wright CY, Coetzee G, Ncongwane K. Seasonal trends in potential sunburn risk among outdoor workers in South Africa using monitored ambient solar UV radiation levels. Occup Health S Afr, 2011, 17(6):22-29. https://www.occhealth.co.za/ ?/viewArticle/1277

[47] Sin CW, Barua A, Cook A. Recurrence rates of periocular basal cell carcinoma following Mohs micrographic surgery: a retrospective study. Int J Dermatol, 2016, 55(9):1044-1047. https://doi.org/10.1111/ijd.13326 PMID: 27152747

[48] Troeltzsch M, Probst FA, Knösel T, Mast G, Ehrenfeld M, Otto $S$. Clinical and pathologic parameters predicting recurrence of facial basal cell carcinoma: a retrospective audit in an advanced care center. Int J Dermatol, 2016, 55(11):12811288. https://doi.org/10.1111/ijd.13341 PMID: 27420481

[49] Bartoš V, Kullová M. Basal cell carcinoma of the skin with mixed histomorphology: a comparative study. Cesk Patol, 2016, 52(4):222-226. PMID: 27869450

[50] Wu A, Sun MT, Huilgol SC, Madge S, Selva D. Histological subtypes of periocular basal cell carcinoma. Clin Exp Ophthalmol, 2014, 42(7):603-607. https://doi.org/10.1111/ceo.12298 PMID: 24533627 
[51] Stanoszek LM, Wang GY, Harms PW. Histologic mimics of basal cell carcinoma. Arch Pathol Lab Med, 2017, 141(11): 1490-1502. https://doi.org/10.5858/arpa.2017-0222-RA PMID: 29072946

[52] Quatresooz P, Martalo O, Piérard GE. Differential expression of alpha1 (IV) and alpha5 (IV) collagen chains in basal-cell carcinoma. J Cutan Pathol, 2003, 30(9):548-552. https://doi. org/10.1034/j.1600-0560.2003.00118.x PMID: 14507402

[53] Goździalska A, Wojas-Pelc A, Drąg J, Brzewski P, Jaśkiewicz J, Pastuszczak M. Expression of metalloproteinases (MMP-2 and MMP-9) in basal-cell carcinoma. Mol Biol Rep, 2016, 43(10): 1027-1033. https://doi.org/10.1007/s11033-016-4040-9 PMID: 27406386 PMCID: PMC5025502

[54] Lesack K, Naugler C. Morphometric characteristics of basal cell carcinoma peritumoral stroma varies among basal cell carcinoma subtypes. BMC Dermatol, 2012, 12:1. https:// doi.org/10.1186/1471-5945-12-1 PMID: 22405101 PMCID: PMC3338565

[55] ShamsiMeymandi S, Dabiri S, ZeynadiniMeymand A, Iranpour M, Khalili M, Alijani S, Aflatoonian M. Evaluation of immunohistochemical findings and clinical features associated with local aggressiveness in basal cell carcinoma. Iran J Pathol, 2019, 14(3):193-196. https://doi.org/10.30699/ijp.2019.82907. 1781 PMID: 31582995 PMCID: PMC6742741

[56] Sahin IH, Uzunparmak B. Comment on: $\alpha$-Smooth muscle actin expression and desmoplastic stromal reaction in pancreatic cancer: results from the CONKO-001 study. Br J Cancer, 2015, 112(11):1838. https://doi.org/10.1038/bjc.2014.663 PMID: 25602961 PMCID: PMC4647247

[57] Song X, Yan L, Lu C, Zhang C, Zhu F, Yang J, Jing H, Zhang H, Qiao J, Guo $H$. Activation of hedgehog signaling and its association with cisplatin resistance in ovarian epithelial tumors. Oncol Lett, 2018, 15(4):5569-5576. https://doi.org/ 10.3892/ol.2018.8008 PMID: 29552194 PMCID: PMC5840551
[58] Horn A, Palumbo K, Cordazzo C, Dees C, Akhmetshina A, Tomcik M, Zerr P, Avouac J, Gusinde J, Zwerina J, Roudaut H, Traiffort E, Ruat M, Distler O, Schett G, Distler JHW. Hedgehog signaling controls fibroblast activation and tissue fibrosis in systemic sclerosis. Arthritis Rheum, 2012, 64(8):2724-2733. https://doi.org/10.1002/art.34444 PMID: 22354771

[59] Katoh M. Genomic testing, tumor microenvironment and targeted therapy of Hedgehog-related human cancers. Clin Sci (Lond), 2019, 133(8):953-970. https://doi.org/10.1042/ CS20180845 PMID: 31036756

[60] Casas BS, Adolphe C, Lois P, Navarrete N, Solís N, Bustamante E, Gac P, Cabané P, Gallegos I, Wainwright BJ, Palma V. Downregulation of the Sonic Hedgehog/Gli pathway transcriptional target Neogenin-1 is associated with basal cell carcinoma aggressiveness. Oncotarget, 2017, 8(48):8400684018. https://doi.org/10.18632/oncotarget.21061 PMID: 29137400 PMCID: PMC5663572

[61] Jacobsen AA, Strasswimmer J. Spontaneous resolution of advanced basal cell carcinoma after short-pulse treatment with hedgehog pathway inhibitor. JAAD Case Rep, 2016, 2(4):360-361. https://doi.org/10.1016/j.jdcr.2016.06.010 PMID: 27626056 PMCID: PMC5011173

[62] Tolani B, Hoang NT, Acevedo LA, Leprieur EG, Li H, He B, Jablons DM. Preclinical characterization of therapeutic antibodies targeted at the carboxy-terminus of Sonic hedgehog. Oncotarget, 2018, 9(18):14311-14323. https://doi.org/10.18632/oncotarget. 24510 PMID: 29581846 PMCID: PMC5865672

[63] Carpenter RL, Ray H. Safety and tolerability of sonic hedgehog pathway inhibitors in cancer. Drug Saf, 2019, 42(2):263-279. https://doi.org/10.1007/s40264-018-0777-5 PMID: 30649745 PMCID: PMC6434684

\section{Corresponding author}

Jelena Moisejenko-Golubovica, MD, Department of Doctoral Studies, Riga Stradins University, 16 Dzirciema Street, LV-1007 Riga, Latvia; Phone +37126048005, e-mail: jelena.moisejenko@gmail.com 